\title{
Comparison of silicone spray versus water soluble lubricating jelly for the aid in bronchoscopic examination
}

\author{
Antonio Hernandez ${ }^{1 *}$, Rachel Cogdill ${ }^{1}$, Carmen Hinojosa-Laborde ${ }^{1}$ and Marcos I. Restrepo ${ }^{2}$ \\ *Correspondence: hernandeza7@uthscsa.edu \\ 'Department of Anesthesiology at the University of Texas Health Science Center at San Antonio, USA. \\ ${ }^{2}$ Department of Pulmonary and Critical Care Medicine at the University of Texas Health Science Center at San Antonio \& South Texas \\ Veterans Health Care System, USA.
}

\begin{abstract}
Objective: Our aim was to compare the efficacy of silicone spray (SS) to water soluble lubricating jelly (WSLJ) as an aid to fiberoptic bronchoscopy, according to time of bronchoscopy, shear forces measured via the endotracheal tube cuff, cost, and survey satisfaction.

Study design: Randomized, crossover experimental design.

Materials \& Methods: We evaluated 19 clinicians performing bronchoscopy on a simulation pulmonary model, after receiving informed consent. Half of the volunteers were randomized to begin the experiment at either the SS or WSLJ manikin, and then crossed over. Volunteers performed bronchoscopy and silently read the message at the end of each mainstem bronchus. Outcomes were evaluated based on time to perform the bronchoscopic exam and peak airway pressure/shear forces, cost, and survey satisfaction defined as quality of view and ease of lubricant use for bronchoscopy.

$\underline{\text { Results: }}$ There were no differences in time $(\mathrm{p}=0.1)$, or peak airway pressure between SS and WSLJ bronchoscopic exams ( $\mathrm{p}=0.7)$. When questioned about quality of bronchoscopic view, 12 subjects ranked SS as having higher quality view than the WSLJ manikin, and the paired rankings were significantly different by Wilcoxon signed-ranks test $(p=0.02)$. Combined view quality and ease of use scores favored SS for 13 volunteers, and the paired rankings were significantly different $(\mathrm{p}=0.03)$.

Conclusions: Although we were unable to identify superiority between these two lubricants based on variables of time and peak pressure, we did identify improved quality of view with SS. In practical use, it is likely that clinicians would prefer SS to WSLJ.
\end{abstract}

Keywords: Bronchoscopy, lubricant, silicone spray, lubricant jelly, airway management, simulation

\section{Background}

The flexible fiberoptic bronchoscope (FOB) is essential for anesthesiology practice and critical care medicine, and has been used for difficult airway management more than any other technique or device. The FOB is imperative for lung isolation techniques and evaluation of the bronchi and distal airways. However, fiberoptic bronchoscopy is not without risks, i.e., injury with repeated attempts to pass an endotracheal tube (ETT) over the FOB into the trachea. A case of laryngeal cyst attributed to fiberoptic nasotracheal intubation has been reported [1]. In a retrospective study at a training institution, the success rate of fiberoptic intubation over a seven year period ranged from $80 \%$ to $95 \%$ [2]. Among experienced practitioners, causes of failed fiberoptic intubation include inability to advance the endotracheal tube over the $F O B$ and inability to withdraw the FOB after successful intubation [3]. Furthermore, the inability to remove the fiberscope from the endotracheal tube and thus compromise of the airway, was associated with a "tight fit" between the endotracheal tube and FOB. Although there has been a description of the preparation of the airway and endotracheal tube, no description of the lubricant is noted, only that it was applied generously. Publications for the use of lubrication for bronchoscopy is limited, with a recent reference involving the use of lubricant ointment versus a cream mixture consisting of $2.5 \%$ lidocaine and $2.5 \%$ prilocaine (EMLA cream) for rigid bronchoscopy. In that publication, Hai Yu and colleagues found excellent bronchoscopic manipulation conditions in $80 \%$ with EMLA as compared to $13 \%$ in the lubricant ointment [4].

The two most commonly used lubricants are SS and WSLJ. It remains unclear if the type of lubricant can impact the time to complete a bronchoscopic exam or shear forces leading to airway trauma. This is an area that is understudied and requires further investigation.

We compared the efficacy of SS to WSLJ as an aid for fiberoptic bronchoscopy. We evaluated the two based upon time to complete a focused bronchoscopic examination, peak pressures exerted during bronchoscopy, and various other factors pertaining to personal preferences using a survey.

\section{Materials and Methods \\ Sample}

This is a randomized, crossover experimental design involving the evaluation of 19 volunteer trained clinicians who performed bronchoscopy on a simulation pulmonary model. Volunteers consisted of faculty, fellows, and residents from 
the departments of anesthesiology and medicine, division of pulmonology and critical care medicine. The inclusion criteria were a) prior experience with fiberoptic intubation or $\mathrm{FOB}, \mathrm{b}$ ) no prior experience with $\mathrm{SS}$, and c) completion of the pre-study briefing during which we described the exercises involved in the experiment. Exclusion criteria were a) failure to demonstrate competence in bronchoscopy during the experiment, b) failure to complete FOB using both SS and WSLJ, and c) failure to complete the survey. To avoid a pattern of improved performance with the second examination, we randomly assigned half of the volunteers to begin with the silicone station and the other half to begin with the WSLJ station.

Two manikins (Laerdal ${ }^{\circledR}$ Airway Management Trainers), designed for instruction of direct laryngoscopy and fiberoptic intubation, were placed on a table and one labeled as "silicone" and the other"lubricating jelly". The lung component was removed and replaced with a box. The back of each box contained two $2.625 \times 1$ inch address labels, each label contained a different message, printed in black ink in Times New Roman font, size 10.

Manikins were intubated with a 7.0 Mallinckrodt intermediate $\mathrm{Hi}$-Lo ${ }^{\oplus}$ cuffed ETT secured with cotton tape at $21 \mathrm{~cm}$ at the lip. Each ETT cuff was inflated with sufficient air to generate a pressure of $15 \mathrm{cmH}_{2} \mathrm{O}$. A cuff pressure gauge (RÜSCH Endotest \#12-112700 for low pressure cuffs) was connected to the pilot balloon in order to measure peak pressures during FOB examination.

Two identical fiberoptic stations (STORZ Endoskopetelecam SL ntcs 20212120) were set up. Both fiberoptic bronchoscopes were assessed by our biomedical personnel who verified that both systems were of equal performance and efficiency before and after each study session. One station was labeled "silicone" and the other "lubricating jelly", and were used with the respective lubricant and manikin to avoid cross contamination of lubricants.

\section{Intervention}

The intervention for the study involved the application of two different lubricants on two separate fiberoptic bronchoscopes with the aim to measure if there would be a difference noted between technical parameters (time and shear forces as measured by peak airway pressures), cost, and survey satisfaction. In the silicone station, the FOB was sprayed once with universal SS (Silkospray by RÜSCH, Cat. No. 556000) along both sides. In the lubricating jelly station, APLICARE lubricating jelly packets (No. 82281) were provided; each packet contained five grams of lubricant. Volunteers were permitted to apply as much WSLJ as desired. At the conclusion of their examination, volunteers documented what they read on the label, onto a sheet of paper provided by the investigators.

\section{Outcome measures}

The following measures were compared between lubricants:
Time for bronchoscopic examination and shear forces measured as peak airway pressure measured at the ETT cuff, cost, and survey satisfaction.

\section{Technical parameters}

a. Time of total bronchoscopic examination, for both right and left mainstem bronchi, using a Sportline digital stopwatch, product number 082020518.

b. Peak ETT cuff pressure during instrumentation.

\section{Cost analysis protocol}

A box of 10 SS cans (Silkospray by RÜSCH, Cat. No. 556000) was opened and the following was done with each can:

a. Weight before use in grams.

b. Sprayed a bronchoscope along one side, twice, and rotated the bronchoscope 180 degrees and sprayed twice again.

c. Weight after use in grams.

Each silicone can was used to spray 10 bronchoscopes. Then we measured the weight before and after use for 10 bronchoscopes, and recorded the difference. This provided the average grams of SS used per bronchoscope. The price of a SS can, divided by the average SS can weight in grams, provided the cost of SS per gram (Table 3). The product of these two provided the cost of SS per bronchoscope. To avoid within-user variation, only one individual participated in the process of spraying silicone during the cost analysis.

\section{Survey satisfaction}

Survey satisfaction questionnaire focused on quality of bronchoscopic view, ease of performing the bronchoscopic exam, and preference of lubricant prior to and after completing the study.

\section{Statistical analysis}

Volunteers were familiar with a standard technique of bronchoscopic lubrication with WSLJ, and unfamiliar with the use of SS for this task. Standard and new technique measures of lubricant efficacy in time to conduct the bronchoscopic exam (seconds), peak airway pressure $\left(\mathrm{cmH}_{2} \mathrm{O}\right)$ as measured at the ETT cuff, quality of view score, and ease of lubricant use score were paired for each participant and compared using Wilcoxon matched-pairs signed-ranks tests. Participants were classified according to their post-experiment technique preference (standard or new), and paired differences of standard minus new measures were compared for standard vs. new technique preference using Mann-Whitney $U$ tests. Summary measures of the median and first and third quartiles were reported, and depicted graphically with box plots. Statistical tests with $p<0.05$ were considered significant, and Stata 10.1 (StataCorp, College Station, TX) software was used.

\section{Results}

Twenty-five subjects with a variety of skill levels participated in this study (Table 1). To ensure that the volunteer sample 
Table 1. Characteristics of subjects involved in study.

\begin{tabular}{lcc}
\hline Subject title & PGY level & $\mathbf{N = 1 9}$ \\
\hline Resident & 2 & 8 \\
& 3 & 4 \\
& 4 & 1 \\
\hline Fellow & 4 & 1 \\
& 5 & 1 \\
& 6 & 2 \\
\hline Attending & NA & 8 \\
\hline
\end{tabular}

$\overline{\mathrm{PGY}}=$ post-graduate year; $\mathrm{NA}=$ not applicable;

$\mathrm{N}=$ number of subjects in category

Table 2. Statistics Comparison between WSJL and silicone lubricants regarding time to perform the exam \& peak airway pressure.

\begin{tabular}{lccc}
\hline Primary Outcome & WSLJ & SS (SS) & $\Delta$ WSLJ - SS \\
\hline Time: & 44.6 & 56.8 & 19.4 \\
Median (IQR) & $(40.8-121.9) \mathrm{sec}$ & $(32.6-84.1) \mathrm{sec}$ & $(-9.5-36.1) \mathrm{sec}$ \\
Pressure: & 34 & 34 & 0 \\
Median (IQR) & $(32-37) \mathrm{cmH}_{2} \mathrm{O}$ & $(32-37) \mathrm{cmH}_{2} \mathrm{O}$ & $(-4-4) \mathrm{cmH}_{2} \mathrm{O}$ \\
\hline
\end{tabular}

Table 3. Cost Analysis for water soluble lubricant jelly and SS.

\begin{tabular}{|c|c|c|c|c|}
\hline Cost of Can & $\begin{array}{l}\text { Average Amount } \\
\text { per Can (grams) }\end{array}$ & $\begin{array}{l}\text { Cost of } \\
\text { SSper gram }\end{array}$ & $\begin{array}{l}\text { SSuse per } 1 \\
\text { bronchoscope grams }\end{array}$ & $\begin{array}{l}\text { Cost of SSper } 1 \\
\text { bronchoscope }\end{array}$ \\
\hline$\$ 40.00$ & 407.87 & $\$ 0.10$ & 2.81 & $\$ 0.28$ \\
\hline $\begin{array}{l}\text { Cost of } \\
\text { lubricant box }\end{array}$ & $\begin{array}{l}\text { Packets per } \\
\text { box }\end{array}$ & $\begin{array}{l}\text { Cost } \\
\text { per packet }\end{array}$ & $\begin{array}{l}\text { Lubricant Packets used } \\
\text { per } 1 \text { scope }\end{array}$ & $\begin{array}{l}\text { Cost of lubricant } \\
\text { per scope }\end{array}$ \\
\hline$\$ 10.65$ & 150 & $\$ 0.07$ & 2 & $\$ 0.14$ \\
\hline
\end{tabular}

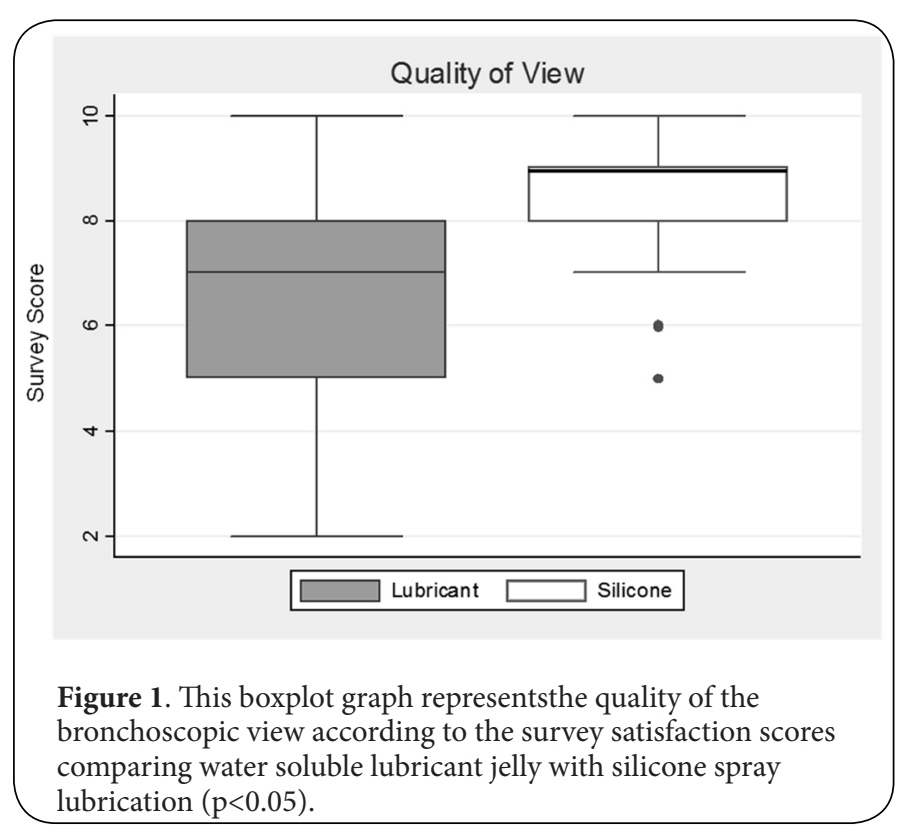

had a reasonably homogeneous bronchoscope lubricating technique, the analysis was restricted to 19 volunteers, who reported that their preferred method of bronchoscopic lubrication was WSLJ. We excluded six subjects due to a prior bias toward SS (1 anesthesiology resident) or a lacri-lube eye ointment(1 anesthesiology resident) and no experience with WSLJ (1 anesthesiology residents), or did not complete the survey ( 3 anesthesiology residents) and were therefore eliminated from the analysis.

All volunteers conducted a complete bronchoscopic examination at both stations. Following their participation, 14 of the 19 subjects (74\%) changed their preference from WSLJ to SS, while 2 others responded with "no preference" as they were bias toward lacri-lube eye ointment and lacked the experience with WSLJ.

There were no statistically significant results related to time, although there was a trend of requiring less time to complete the FOB when SS was used when as compared to WSLJ. The time required to complete an exam varied widely, indicating a considerable disparity in the level of experience among volunteers (Table 2). Measurements ranged from 19.4 to 350.6 seconds. Nine volunteers were able to complete both procedures within one minute, while 5 volunteers required more than one minute for both lubricant stations, which correlated to their degree of experience with FOB. The paired WSLJ and SS time intervals were compared using a Wilcoxon signed-ranks test, which indicated no significant differences $(p=0.1)$.When comparing the 14 volunteers that changed their preference from WSLJ to SS vs. the other 5 volunteers that maintained their initial preference of WSLJ, no significant differences were observed for WSLJ minus SS time difference values by Mann-Whitney $U$ test $(p=0.17)$.

Pressure exerted during the examination and measured at the ETT cuff as shear force ranged from $30-44 \mathrm{cmH}_{2} \mathrm{O}$. Differences in ETT cuff pressure ranged from 0 to $5 \mathrm{~cm}$, and no significant differences in WSLJ and SSpressures were observed by Wilcoxon signed-ranks test $(p=0.61)$. WSLJ minus SS maximum pressure difference values were not significantly different for volunteers that changed preference vs. others by Mann-Whitney $U$ test $(p=1.00)$.

All participants completed a survey. When questioned about quality of bronchoscopic view, 12 of 19 subjects ranked the SS manikin as having a higher quality view than the WSLJ manikin, and the paired rankings were significantly different by Wilcoxon signed-ranks test $(p=0.02)$, see Figure 1 . When asked to quantify the ease of exam, 11 of 19 subjects ranked the SS higher, but the paired rankings were not significantly different ( $p=0.12$ ), see Figure 2 . Also, combined view quality and ease of use scores favored SS for 13 of 19 volunteers, and the paired rankings were significantly different $(p=0.03)$. The cost of SS use was determined to be $\$ 0.28$ per bronchoscope. The cost of lubricant for a single use was determined to be half of that for SS, $\$ 0.14$ (Table 3).

\section{Discussion}

The current study was designed to evaluate the efficacy of SS as a lubricant when compared to WSLJ as an aid for FOB according to technical parameters, cost and volunteer survey satisfaction response. We aimed to identify if one lubricant 


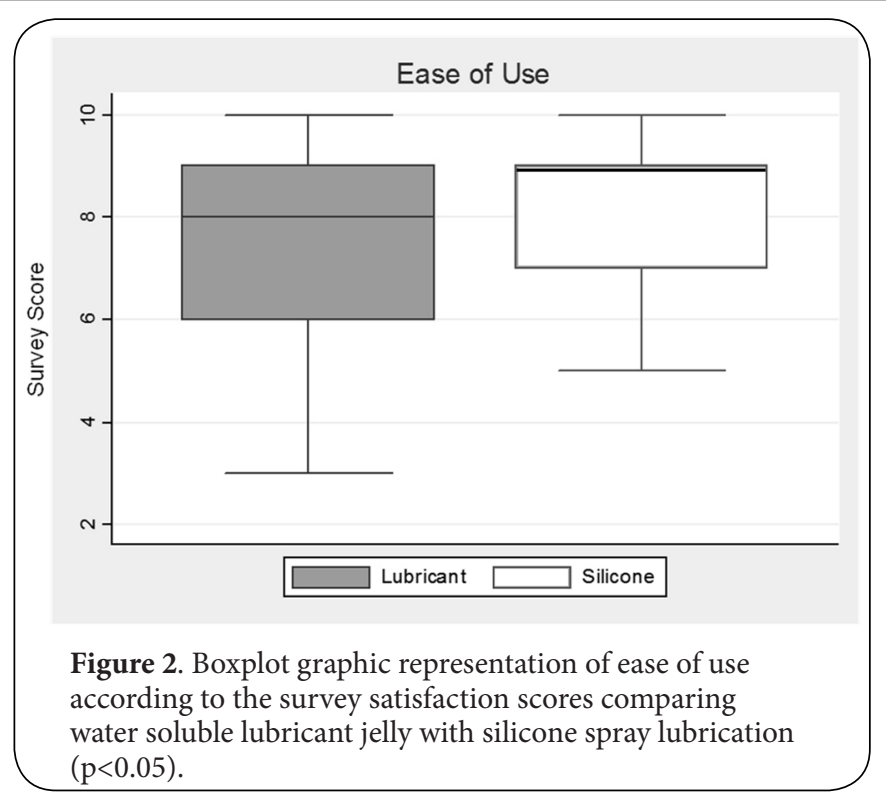

was superior over the other by reducing the time to conduct a bronchoscopic examination. There were no differences between either lubricant, with regard to the time it took to perform the bronchoscopy or the degree of peak pressure generated during the procedure. There was a higher evaluation score associated with SS with regard to the quality of view. In addition, at the conclusion of the study there was a greater preference for SS over WSLJ.

Time to perform a bronchoscopy is important due to its impact on the patient's physiology, morbidity, and overall cost. Although rather infrequent, injury due to bronchoscopy does occur. In a study by Kerwin AJ et al., they studied bronchoscopy in patients with brain injury [5]. In their study, they noted a direct correlation between time of bronchoscopy and an increase in intracranial pressure (ICP). This increase in ICP from bronchoscopy was noted in patients with a baseline ICP of $<10 \mathrm{~mm} \mathrm{Hg}$ and $>10 \mathrm{~mm} \mathrm{Hg}$. In their study, they noted ICP increase in at least $50 \%$ of patients in $88 \%$ of their procedures and an ICP increase at least 100\% in 69\% of their procedures. The average time to achieve a baseline ICP was 15 minutes. In relatively healthier patient population, time also seems to be of importance. In a study by Hirose $T$ et al., the reviewed patient satisfaction related to flexible bronchoscopy [6]. Of the various elements studied to include the type of procedure and sedation, time of bronchoscopy was the element that was most significant; the greater the time of bronchoscopy associated with the lower satisfaction. One of our study aims was to evaluate the impact on cost for using SS when compared to WSLJ. Although in some institutions cost of bronchoscopy in the operating room is not a factor [7], cost can be incurred via damage to the equipment and patient due to lack of adequate lubrication [8]. A study by Kirkpatrick MB et al., notes cost associated to bronchoscope damage during the insertion of the bronchoscope through the endotracheal tube or tracheostomy tube [9]. The cost of repairing a flexible fiberoptic bronchoscope varies based on the degree of damage, but can be in the range of $\$ 5,000$ to $\$ 8,000$. A side from cost, we also examined if there was a preference toward either of the lubricants based on a satisfaction survey.

Our satisfaction survey focused on ease of use of the lubricant, and separately the quality of view. Our study found a better quality of view associated with the SS as compared to the WSLJ. In addition, 14 of the participants reported at the conclusion of the study that they had changed their preference for FOB lubricant from WSLJ to SS. We decided to study personal preference since this is likely to impact what providers will use in their practice.

\section{Conclusion}

In conclusion, there were no differences regarding time of the procedure or peak pressures generated during the procedure. We did find a significant association with better quality of view to the SS lubricant. Larger studies need to be conducted on human subjects in order to determine if there is an impact on the type of lubricant used for fiberoptic bronchoscopy. There has been focus on preparation of the patient for bronchoscopy $[10,11]$, but little on the preparation of the bronchoscope related to specific lubrication [4]. Overall, our findings tend to favor the use of SS over WSLJ. Based on our observations, it is likely that clinicians would have a greater preference for SS for their clinical practice.

\section{Competing interests}

The authors declare that they have no competing interests.

\section{Acknowledgement}

John School field. Statistician. Department of Academic Technology Services at the University of Texas Health Science Center at San Antonio. Role: Data Analysis and manuscript.

\section{Publication history}

Received: 01-Jan-2013 Revised: 17-Jan-2013

Accepted: 21-Jan-2013 Published: 30-Jan-2013

\section{References}

1. Smith BL: Laryngeal cyst following fibreoptic intubation. Anaesthesia 1986, 41:430-1. | Article | PubMed

2. Connelly NR, Ghandour K, Robbins L, Dunn S and Gibson C: Management of unexpected difficult airway at a teaching institution over a 7-year period. J Clin Anesth 2006, 18:198-204. | Article | PubMed

3. Weiss YG and Deutschman CS: The role of fiberoptic bronchoscopy in airway management of the critically ill patient. Crit Care Clin 2000, 16:445-51. | Article | PubMed

4. Yu H, Yang XY, Liu B (2009) Yu H, Yang XY and Liu B: EMLA Cream coated on the rigid bronchoscope for tracheobronchial foreign body removal in children. Laryngoscope 2009, 119:158-61. I Article I PubMed

5. Kerwin AJ, Croce MA, Timmons SD, Maxwell RA, Malhotra AK and Fabian TC: Effects of fiberoptic bronchoscopy on intracranial pressure in patients with brain injury: a prospective clinical study. J Trauma 2000, 48:878-82; discussion 882-3. | Article | PubMed

6. Hirose T, Okuda K, Ishida H, Sugiyama T, Kusumoto S, Nakashima M, Yamaoka T and Adachi M: Patient satisfaction with sedation for flexible bronchoscopy. Respirology 2008, 13:722-7. | Article I PubMed 
Hernandez et al. Journal of Anesthesiology and Clinical Science 2013, http://www.hoajonline.com/journals/pdf/2049-9752-2-7.pdf

7. Levin R and Trivikram L: Cost/benefit analysis of open tracheotomy, in the or and at the bedside, with percutaneous tracheotomy. Laryngoscope 2001, 111:1169-73. I Article I PubMed

8. Ovassapian A, Yelich S J, Dykes M H and Brunner E E: Fiberoptic nasotracheal intubation--incidence and causes of failure. Anesth Analg 1983, 62:692-5. | Article | PubMed

9. Kirkpatrick MB, Smith JR, Hoffman PJ and Middleton RM, 3rd: Bronchoscope damage and repair costs: results of a regional postal survey. Respir Care 1992, 37:1256-9. | Article | PubMed

10. Pickles J, Jeffrey M, Datta A and Jeffrey AA: Is preparation for bronchoscopy optimal? Eur Respir J 2003, 22:203-6. | Article I PubMed

11. Wahidi MM, Jain P, Jantz M, Lee P, Mackensen GB, Barbour SY, Lamb $C$ and Silvestri GA: American College of Chest Physicians consensus statement on the use of topical anesthesia, analgesia, and sedation during flexible bronchoscopy in adult patients. Chest 2011, 140:134250. | Article | PubMed

\section{Citation:}

Hernandez A, Cogdill R, Hinojosa-Laborde C and Restrepo $\mathrm{M}$ I: Comparison of silicone spray versus water soluble lubricating jelly for the aid in bronchoscopic examination. journal of Anesthesiology and Clinical Science 2013, 2:7.

http://dx.doi.org/10.7243/2049-9752-2-7 